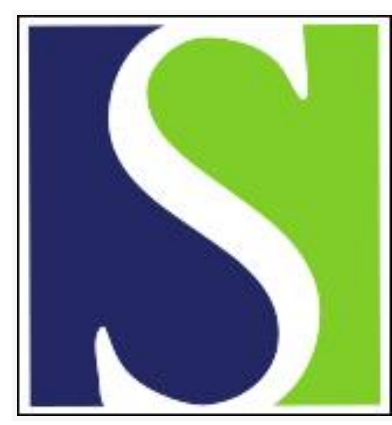

Scand J Work Environ Health 1992;18(4):257-261

https://doi.org/10.5271/sjweh.1580

Issue date: 01 Aug 1992

Seasonal variation in neck and shoulder symptoms.

by Takala E-P, Viikari-Juntura E, Moneta GB, Saarenmaa K, Kaivanto K

Affiliation: Institute of Occupational Health, Helsinki, Finland.

The following article refers to this text: $2014 ; 40(3): 244-251$

This article in PubMed: www.ncbi.nlm.nih.gov/pubmed/1411369 


\title{
Seasonal variation in neck and shoulder symptoms
}

\author{
by Esa-Pekka Takala, DMedSc, Eira Viikari-Juntura, DMedSc, Giovanni B Moneta, PhD, \\ Kari Saarenmaa, MSc, Kim Kaivanto ${ }^{1}$
}

\begin{abstract}
TAKALA E-P, VIIKARI-JUNTURA E, MONETA GB, SAARENMAA K, KAIVANTO K. Seasonal variation in neck and shoulder symptoms. Scand $J$ Work Environ Health 1992;18:257-61. The objective of the investigation was to study the course of neck and shoulder symptoms and the predictors for these symptoms among women in light sedentary work. Postal surveys were conducted among 351 tellers (age 20-50 years) of a bank company in September, December, March, and May. The response rates were $74-90 \%$. The outcome was the frequency of the symptoms during the previous three months. In the analysis, univariate explorations and random-effects logistic binomial regression for distinguishable responses were used. A change in the frequency of neck and shoulder symptoms was seen in $40.5 \%$ of the subjects during the follow-up period from autumn to spring. The frequency of the symptoms decreased from autumn and winter towards spring. The stability of the frequency of the symptoms was positively associated with age. Seasonal variation in symptoms should be considered when preventive programs against neck and shoulder disorders are planned and evaluated.
\end{abstract}

Key terms: bank teller, cervicobrachial disorders, longitudinal study, musculoskeletal disorders, sedentary work, random-effects regression.

Neck and shoulder symptoms are common in several occupations. In cross-sectional studies, symptoms have been linked to jobs with highly repetitive shoulder muscle contractions, static contractions, and work above shoulder level (1-5). In addition to biomechanical factors, psychosocial elements such as poor job satisfaction have been associated with neck and shoulder symptoms $(3,6-9)$.

Few longitudinal studies have been reported on neck and shoulder symptoms and associated factors. In a study of 69 women working in the electronics industry (6), predictors of deterioration of the symptoms were previous physically heavy jobs and previous sick leave. Predictors of improvement were reallocation and physical activity in spare time. High productivity predicted deterioration after one year but improvement after two years. Predictors of "remaining healthy" were work without elevating the shoulders and satisfaction with work tasks. In another study of 83 female assembly-line workers, type A personality, high productivity, and duration of employment were associated with a deterioration in neck and shoulder disorders during a follow-up of two years (10).

When interventions against neck and shoulder disorders are planned or evaluated, we need to know both the risk factors and the natural course of the disorders. In a follow-up of 327 men (age $47-62$ years), the frequency of neck and shoulder symptoms did not differ after three years, except among the still active manual workers, who reported more symptoms (11). In another study among 50 female data entry operators (12),

\footnotetext{
1 Institute of Occupational Health, Helsinki, Finland.
}

Reprint requests to: Dr E-P Takala, Topeliuksenkatu 41 a A, SF-00250 Helsinki, Finland. the prevalence of neck and shoulder symptoms was similar in three cross-sectional surveys $(0,6$ and 12 months), but about $60 \%$ of the subjects had some change in the frequency of the symptoms during the follow-up. Most of the subjects who had no symptoms in the first survey remained unsymptomatic.

The aim of the present investigation was to study the course of neck and shoulder symptoms among women in light sedentary work.

\section{Subjects and methods}

All female cash tellers aged $20-50$ years, altogether 380 women, were selected from the personnel register of a large bank company. A questionnaire concerning neck and shoulder symptoms and related factors was sent to them in September 1988. Twenty-nine women were excluded from the study because they were not active as tellers during the entire study period; therefore the study population comprised 351 women (median age 40 years). Follow-up surveys were carried out in December 1988, March 1989, and at the end of May 1989. The time interval between the successive surveys was about three months, except between the March and May surveys, for which the interval was about twoand-a-half months. The first questionnaire asked the subjects how many days they had had neck and shoulder symptoms during the preceding 12 months (13). In the follow-up questionnaires the questions were the same, but concerned the previous three months (twoand-a-half months in May).

A week prior to each questionnaire informative articles about the study were published in the company's newspaper. Information on the goals and general de- 
sign of the study was included in the letter accompanying each questionnaire. For those women who did not respond, a reminder questionnaire was sent after one and two weeks.

The response rates of the four surveys were $90 \%$ $(\mathrm{N}=316), 85 \%(\mathrm{~N}=297), 74 \%(\mathrm{~N}=261)$, and $76 \%$ $(\mathrm{N}=268)$. Altogether $228(65 \%)$ women responded to all four questionnaires, and $274(78 \%)$ responded to at least three of them.

Bank teller's work is mainly sedentary and physically light, the tasks being similar to many other types of office work. An observational analysis of one workday for 20 women showed that the most repetitive manual tasks were typing and handling banknotes or receipts (14). No requirements for the generation of high physical force were identified. The tellers' workstations had been standardized a few years earlier.

The predictors were age, season (December questionnaire: autumn; March questionnaire: winter; May questionnaire: spring), frequency of neck and shoulder symptoms during the 12 months preceding the base-line survey, score for work characteristics (mean of 29 items in the base-line survey) (15), reported stress ( 6 categories), stress symptoms (18 items), stressful life experiences (19 items) (16), use of spectacles, history of infectious diseases during the preceding three months, and questions on life-style (smoking, physical exercise, and hobbies which impose a static muscular load on the shoulders).

The outcome variable was the frequency of neck and shoulder symptoms (symptoms for $0-7 \mathrm{~d}, 8-30 \mathrm{~d}$, and $>30 \mathrm{~d}$ ) during the preceding three-month (twoand-a-half months in May) interval reported in December, March, and May.

Since age and the frequency of the symptoms during the 12 months preceding the base-line survey were asked about in the September questionnaire, only the 316 subjects who answered that questionnaire were kept in the analysis. The actual sample size and total number of observations for the several analyses were further reduced by item nonresponse.

In the preliminary analysis of the data, all of the predictors were cross-tabulated with the outcome variable. Age, frequency of symptoms during the 12 months preceding the base-line survey, and season showed univariate associations with the outcome variable and were selected for the multivariate analysis.

Random-effects logistic binomial regression for distinguishable responses was used (17), and the data analysis was carried out with the epidemiologic package EGRET $^{\circledR}$ (18). The reason for this choice was twofold. First, the data were longitudinal, and thus the responses were correlated between the subjects' own responses. A within-subject correlation of responses typically results in extrabinomial variation that may introduce severe bias in the testing and estimation of the effects in the model. The technique chosen allowed for the estimation and control of extrabinomial variation. Second, this technique also allowed for those subjects with incomplete data in one or more questionnaires to be kept in the analysis, with a considerable gain in efficiency.

Two separate models were fitted on the odds of $8-30 \mathrm{~d}$ versus $0-7 \mathrm{~d}$ (model 1$)$ and $>30 \mathrm{~d}$ versus 0-7 d (model 2). Base-line symptoms (BASE) and season (SEASON) were treated as categorical predictors. For reasons of efficiency, age was treated as a linear predictor.

The model for the ith subject and jth response was:

$$
\begin{aligned}
\log \left(\mathrm{P}_{\mathrm{ij} 1} / \mathrm{P}_{\mathrm{ij} 0}\right)= & \mu+\beta_{1} \text { BASE }_{\mathrm{i}}+\beta_{2} \text { AGE }_{\mathrm{i}} \\
& +\beta_{3} \operatorname{SEASON~}_{\mathrm{j}}+\sigma \mathrm{u}_{\mathrm{i}},
\end{aligned}
$$

where $\mathrm{j}=1$ (autumn), 2 (winter), 3 (spring); $P_{\mathrm{ij} 0}$ was the probability of subject $i$ being in class " $0-7 \mathrm{~d}$ " in season $\mathrm{j} ; \mathrm{P}_{\mathrm{ij} 1}$ was the probability of subject $\mathrm{i}$ being in class "8-30 d" (for model 1) or " $>30 \mathrm{~d}$ " (for model 2 ) in season $j ; \mu$ was the grand mean effect; BASE $_{i}$ was the subject's response concerning the preceding 12 months and $\beta_{1}$ was its effect; $\mathrm{AGE}_{\mathrm{i}}$ was the subject's age in years and $\beta_{2}$ was its effect; $\operatorname{SEASON}_{j}$ was the season and $\beta_{3}$ was its effect; $\sigma$ was a scale parameter greater than or equal to zero with a constant value for every subject $\mathrm{i}$ and season $\mathrm{j}$; $\mathrm{u}_{\mathrm{i}}$ was an individual difference component, specific to subject $i$ and constant across season $\mathrm{j}$, which was assumed to be randomly distributed over the population of respondents according to a symmetric standardized binomial distribution. The random effect $\left(\sigma u_{i}\right)$ accounted for the within-subject correlation of responses and thus for the extrabinomial variation.

The overall significance of each predictor was evaluated with the use of the likelihood ratio chi-square of difference upon removal of the predictor from the model. The hypothesis that the season effect varied depending on age was parameterized in the form of the interaction of age and season. The significance of this hypothesis was evaluated by the likelihood ratio chisquare of difference upon addition of the interaction term to the model. The evaluation of the extrabinomial variation parameter was based on the likelihood ratio chi-square of difference upon its removal from the model. The square root of the likelihood ratio chisquare of difference was compared with the one-tailed standard normal distribution. The significance of single contrasts (odds ratios) was evaluated with the use of the normal test. P-values of 0.05 or less were considered to be statistically significant.

Model 1 was fitted on 648 observations over 266 subjects, and model 2 on 608 observations over 273 subjects.

\section{Results}

\section{Course of symptoms}

In the base-line survey $136(43 \%)$ subjects reported having had neck and shoulder symptoms more than $30 \mathrm{~d}$ during the previous 12 months. 
A change in the frequency of neck and shoulder symptoms was seen for $40.5 \%$ of the subjects during the follow-up period from December to May (figure 1 and table 1$)$. Twenty-two subjects $(9.6 \%)$ reported a high frequency of symptoms ( $>30 \mathrm{~d}$ ) during the previous 12 months and during each three-month period. Exploration of the data suggested that there was a tendency towards a decreasing frequency of symptoms over time, especially during spring from March to May. Age, reported stress, and the score for the work characteristics in the base-line questionnaire appeared to be associated with neck and shoulder symptoms (19). None of the subjects in the youngest age group ( $<36$ years) reported experiencing symptoms more than $30 \mathrm{~d}$ during the preceding three months in any of the three cross-sectional surveys from December to May.

\section{Multivariate analysis}

For both models of neck and shoulder symptoms, the effect of season was highly significant (table 2) $\left[\chi^{2}=17.5\right.$, degrees of freedom $(\mathrm{df})=2, \mathrm{P}<0.001$; $\left.\chi^{2}=24.6, \mathrm{df}=2, \mathrm{P}<0.001\right]$. In particular, the improvement in the winter relative to the autumn was not significant, and the improvement in the spring was highly significant $(\mathrm{P}<0.001$ for both models).

For both models, the effect of base-symptoms was highly significant $\left(\chi^{2}=79.9, \mathrm{df}=2, \mathrm{P}<0.001 ; \chi^{2}=\right.$ $108.7, \mathrm{df}=2, \mathrm{P}<0.001$ ), a finding indicating a strong carry-over effect of neck and shoulder symptoms experienced in the previous year. For both models, the odds ratios of season and base-line symptoms achieved significance (model 1: $\mathrm{P}<0.001, \mathrm{P}<0.001$; model 2: $\mathrm{P}=0.048, \mathrm{P}<0.001$ ), the odds ratios increasing from $8-30 \mathrm{~d}$ to $>30 \mathrm{~d}$ for base-line symptoms and decreasing for season.

The linear effect of age was not significant for model 1 but was strong and highly significant for model 2 $(\mathrm{P}<0.001)$, th: estimated odds ratio indicating a higher frequency for the older subjects.
The extrabinomial variation was high for both models (2.69 and 4.17) and highly significant $(z=8.73$, $P<0.001$ and $\mathrm{z}=7.96, \mathrm{P}<0.001)$, a finding indicating

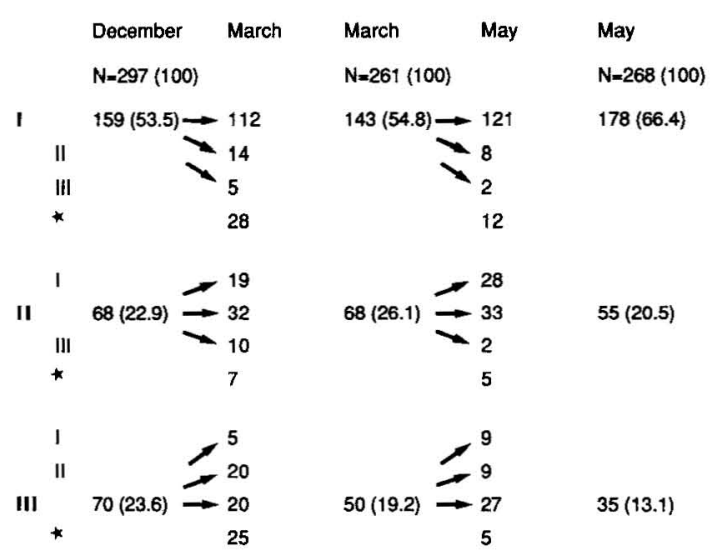

Figure 1. Occurrence of neck and shoulder symptoms in three cross-sectional surveys. Frequency (percentage in parentheses) in three symptom categories. The arrows show the direction and number of subjects changing symptom category in successive surveys. $(1=$ no symptoms or symptoms $<8 \mathrm{~d}$ during the previous three months, $I I=$ symptoms $8-30 \mathrm{~d}$ during the previous three months, III = symptoms $>30 \mathrm{~d}$ during the previous three months, ${ }^{*}=$ missing data)

Table 1. Course of neck and shoulder symptoms. Percentage of subjects who remained in or changed symptom category ( $<8 \mathrm{~d}, 8-30 \mathrm{~d}$, or $>30 \mathrm{~d}$ during the previous three months) in three successive cross-sectional surveys (DecemberMarch-May) $(\mathrm{N}=232)$.

\begin{tabular}{lr}
\hline Symptom category & $\%$ \\
\hline All three the same & 59.5 \\
$<8 \mathrm{~d}$ & 42.7 \\
$8-30 \mathrm{~d}$ & 7.3 \\
$>30 \mathrm{~d}$ & 9.5 \\
Change in frequency of symptoms & 40.5 \\
Less frequent & 23.7 \\
More frequent & 5.6 \\
Fluctuation in frequency & 11.2 \\
\hline
\end{tabular}

Table 2. Odds ratios (OR) and their $95 \%$ confidence intervals $(95 \% \mathrm{Cl})$ for the mutually adjusted effects of three predictors of neck and shoulder symptoms.

\begin{tabular}{|c|c|c|c|c|}
\hline \multirow{2}{*}{ Predictor contrast } & \multicolumn{2}{|c|}{$\begin{array}{c}\text { Model } 1 \\
(8-30 \text { d versus } 0-7 \text { d) }\end{array}$} & \multicolumn{2}{|c|}{$\begin{array}{c}\text { Model } 2 \\
(>30 \text { d versus } 0-7 d)\end{array}$} \\
\hline & OR & $95 \% \mathrm{Cl}$ & OR & $95 \% \mathrm{Cl}$ \\
\hline \multicolumn{5}{|l|}{ Base-line symptoms } \\
\hline $\begin{array}{l}0-7 d \\
8-30 d \\
>30 d\end{array}$ & $\begin{array}{c}1.00 \\
16.3 \\
166\end{array}$ & $\begin{array}{l}4.12-64.5 \\
34.3-805\end{array}$ & $\begin{array}{c}1.00 \\
15.6 \\
13900\end{array}$ & $\begin{array}{l}1.04-233 \\
283-683000\end{array}$ \\
\hline \multicolumn{5}{|l|}{ Age } \\
\hline Per one year & 1.04 & $0.97-1.12$ & 1.29 & $1.10-1.50$ \\
\hline \multicolumn{5}{|l|}{ Season } \\
\hline $\begin{array}{l}\text { Autumn } \\
\text { Winter } \\
\text { Spring }\end{array}$ & $\begin{array}{l}1.00 \\
0.91 \\
0.28\end{array}$ & $\begin{array}{c}\cdot \\
0.47-1.76 \\
0.14-0.56\end{array}$ & $\begin{array}{l}1.00 \\
0.50 \\
0.07\end{array}$ & $\begin{array}{c}0.17-1.45 \\
0.02-0.25\end{array}$ \\
\hline
\end{tabular}


that the responses had a high within-subject correlation.

The interaction between age and season was significant for model $1(\mathrm{P}=0.045)$, the parameter estimate suggesting that the improvement from winter to spring was stronger for the younger subjects. The interaction was not significant for model 2 .

We examined possible departures from the hypothesis of linear age trend by refitting all of the models with the predictor age categorized in five age classes of five-year range each and factorized in four contrasts. There was no evidence of a nonlinear trend for age, and the estimates of the other predictors in the equation were virtually the same as those obtained in the models with linear age.

The effect of work characteristics was not statistically significant when work characteristics were added to the model.

\section{Discussion}

Our results confirm the reported fluctuation in neck and shoulder symptoms (12). Neck and shoulder symptoms in light sedentary work seem to be generally benign and the symptoms come and go. However, $10 \%$ of the subjects repeatedly reported a high frequency of these symptoms. A Swedish study followed 37 women who had visited their health care unit at least 15 times during 1979 due to neck and shoulder ailments while working in the car industry (20). All of the women reported frequent and disabling neck and shoulder pain in 1989, even those who were no longer active workers. The results of other studies and our study suggest that a minority of subjects with neck and shoulder symptoms have their symptoms for several months, possibly for several years.

In the present study, older age was a significant predictor of a high frequency of symptoms ( $>30 \mathrm{~d}$ in successive surveys). Because most of the subjects had performed similar tasks during all of their years at work, it was impossible to separate the potential causal effects of the duration of the work per se from age. The frequency of cervical degeneration increases with age $(21,22)$. Hence permanent symptoms may be related to degenerative changes in the cervical spine. The analysis of the tellers' work did not show that the mechanical loads imposed on the neck and shoulders would be of a magnitude that could, according to present knowledge, cause degeneration.

Seasonal variation in neck and shoulder symptoms was a new finding which we have not seen reported in connection with musculoskeletal disorders. Change in work load is not a likely explanation because there was no seasonal variation in bank tellers' work from autumn to spring. The time period in spring was about two weeks shorter than that in autumn and winter. If the reduction in the frequency of the symptoms was due to a slightly shorter cumulation time, a part of those subjects who would have reported symptoms
" $>30$ d" for a three-month period might have answered " $8-30 \mathrm{~d}$ " for a two-and-a-half month period. This occurrence should have resulted in an increase in the subjects' responses in the category " $8-30 \mathrm{~d}$ " in May. No such increase was seen, however; instead there was a decrease.

"Seasonal affective disorder"' is characterized by recurrent winter depression and other mental and physical symptoms, but musculoskeletal symptoms have not been linked to this disorder $(23-25)$. We performed additional analyses with stress and headache as outcomes. A seasonal variation similar to that detected in the analysis of neck and shoulder symptoms was found for these outcomes too.

Stress and neck and shoulder symptoms covaried over time, but age was not related to stress. Despite the longitudinal design of this study, it is not possible to draw conclusions concerning the potential causal relationships between stress and neck and shoulder symptoms. For this purpose, an incidence study should be conducted on unsymptomatic subjects. Our unsymptomatic population was too small for such a study.

Previous symptoms were the strongest predictor of neck and shoulder symptoms. A similar result has been reported concerning neck pain (26) and sciatica (27). This information may be of importance for an occupational health physician when making clinical decisions. For preventive purposes it is of little use because previous symptoms are themselves in fact an effect of other largely unknown predictors. To obtain more information on these predictors, studies on the incidence of neck and shoulder symptoms or disorders are needed.

Recall error is a potential source of bias in retrospective questionnaire studies. The responses of the Nordic questionnaire have been compared with those of an interview (28). The results suggested that people may have difficulties with remembering the total number of days with symptoms during the previous 12 months. In our study the time period was shorter (3 months), and so the number of days was probably easier to remember. It can be argued that some people may have misclassified their symptoms, especially if the number of days was close to the discrimination points of 8 or $30 \mathrm{~d}$. This kind of misclassification is a potential source of error in a comparison of adjacent categories ( $<8 \mathrm{~d}$ versus $8-30 \mathrm{~d}$ or $8-30 \mathrm{~d}$ versus $>30 \mathrm{~d})$. The significant results obtained when contrasting the extremes in symptom frequency (ie, $>30 \mathrm{~d}$ versus $0-7 \mathrm{~d}$ ) probably describe true differences in our study population.

A seasonal variation in symptoms should be considered when preventive programs for neck and shoulder disorders are planned and evaluated. The need for reference groups in intervention studies is emphasized. In addition, the reference population should be observed at the same point in time as the intervention group. 


\section{Acknowledgments}

This study was financially supported by the Finnish Work Environment Fund.

\section{References}

1. Hagberg M, Wegman DH. Prevalence rates and odds ratios of shoulder-neck diseases in different occupational groups. Br J Ind Med 1987;44:602-10.

2. Amano M, Umeda G, Nakajima H, Yatsuki K. Characteristics of work actions of shoe manufacturing assembly line workers and a cross-sectional factor-control study on occupational cervicobrachial disorders. Jpn J Ind Health 1988;30:3-12.

3. Tola S, Riihimäki H, Videman T, Viikari-Juntura E, Hänninen $K$. Neck and shoulder symptoms among men in machine operating, dynamic physical work and sedentary work. Scand J Work Environ Health 1988;14:299305.

4. Ohlsson K, Attewell R, Skerfving S. Self-reported symptoms in the neck and upper limbs of female assembly workers: impact of length of employment, work pace, and selection. Scand J Work Environ Health 1989;15: 75-80.

5. Milerad E, Ekenvall L. Symptoms of the neck and upper extremities in dentists. Scand J Work Environ Health 1990;16:129-34.

6. Jonsson BG, Persson J, Kilbom A. Disorders of the cervicobrachial region among female workers in the electronics industry: a two-year follow up. Int J Ind Ergon 1988;3:1-12.

7. Linton SJ, Kamwendo K. Risk factors in the psychosocial work environment for neck and shoulder pain in secretaries. J Occup Med 1989;31:609-13.

8. Lehto T. Health of the dentist with reference to workrelated and individual factors [dissertation]. Turku (Finland): Social Insurance Institution, 1990. (Publications of the Social Insurance Institution; ML:99.)

9. Kamwendo K. Neck and shoulder disorders in secretaries: prevalence, risk factors, and neck school intervention [dissertation]. Lund (Sweden): University of Lund, 1991.

10. Hägg GM, Suurküla J, Kilbom $\AA$. Prediktorer för belastningsbesvär i skuldra/nacke: en longitudinell studie på kvinnliga montöver [Predictors for work related shoulder/neck disorders: a longitudinal study of female assembly workers]. Stockholm: Arbetarskyddsverket, 1990. (Arbete och hälsa; 10.) (English summary.)

11. Berg M, Sanden $\AA$, Torell G, Järvholm B. Persistence of musculoskeletal symptoms: a longitudinal study. Ergonomics 1988;31:1281-5.

12. Takala E-P, Kukkonen R. Atk-kirjoittajien niska-hartiavaivojen kliiniset löydökset ja oireiden kulku [Neckshoulder symptoms of data entry operators; clinical findings and course of symptoms]. Suom Lääkäril 1988;43: 819-22.

13. Kuorinka I, Jonsson B, Kilbom À, Vinterberg $H$, Biering-Sørensen F, Andersson G, et al. Standardised Nordic questionnaires for the analysis of musculoskeletal symptoms. Appl Ergon 1987;18:233-7.

14. Takala E-P, Viikari-Juntura E. Muscular activity in simulated light work among subjects with neck-shoulder pain. Int J Ind Ergon 1991;8:157-64.

15. Leppänen A. Measurement of work characteristics by questionnaire methods. Acta Psychol Fenn 1986;11: $79-97$.

16. Johnson JH, Sarason IG. Recent developments in research on life stress. In: Hamilton V, Warburton DM, ed. Human stress and cognition: an information processing approach. Chichester (England): John Wiley \& Sons, 1979:205-33.

17. Mauritsen RH. Logistic regression with random effects [dissertation]. Seattle, WA: Department of Biostatistics, University of Washington, 1984.

18. Statistics and Epidemiology Corporation and Cytel Software Corporation. EGRET: reference manual. 1st draft. Seattle, WA: Statistics and Epidemiology Corporation and Cytel Software Corporation, 1985-1990.

19. Takala E-P, Viikari-Juntura E, Moneta G, Saarenmaa $K$, Kaivanto K. Predictors for the natural course of neckshoulder symptoms and headache in light sedentary work. In: Queinnec Y, Daniellou F, ed. Designing for everyone: proceedings of the eleventh congress of the International Ergonomics Association, Paris 1991; vol I. London: Taylor \& Francis, 1991:129-31.

20. Ekenbäck K, Hagberg M. Dålig prognos vid svåra nackskulderbesvär [Poor prognosis of severe neck-shoulder symptoms]. Läkartidningen 1991;88:1120-1.

21. Friedenberg ZB, Miller WT. Degenerative disc disease of the cervical spine. J Bone Joint Surg 1963; 45-A: $1171-8$.

22. Lawrence JS. Disc degeneration: its frequency and relationship to symptoms. Ann Rheum Dis 1969;28:121-37.

23. Jacobsen FM, Wehr TA, Sack DA, James SP, Rosenthal NE. Seasonal affective disorder: a review of the syndrome and its public health implications. Am J Public Health 1987;77:57-60.

24. Blehar MC, Rosenthal NE. Seasonal affective disorders and phototherapy: report of a National Institute of Mental Health-sponsored workshop. Arch Gen Psychiatry 1989;46:469-74.

25. Wehr TA, Rosenthal NE. Seasonality and affective illness. Am J Psychiatry 1989;146:829-39.

26. Riihimäki $H$, Hänninen $K$, Luopajärvi $T$, Mattsson $T$, Waris P, Wickström G, et al. Raudoittaja- ja maalaritutkimus. Osa 6: raudoittajien tuki- ja liikuntaelimistön tilan 5 vuoden seuranta [Study of concrete reinforcement workers and maintenance house painters: part 6: the condition of the reinforcement workers' musculoskeletal system after a follow-up period of five years]. Helsinki: Institute of Occupational Health, 1981. (Työterveyslaitoksen tutkimuksia; vol 172.) (English summary.)

27. Riihimäki H, Wickström G, Hänninen $K$, Luopajärvi $T$. Predictors of sciatic pain among concrete reinforcement workers and house painters - a five-year followup. Scand J Work Environ Health 1989;15:415-23.

28. Kemmlert K, Kilbom Å. Besvär i nacke/skuldra och samband med arbetssituation [Musculo-skeletal trouble in the neck and shoulder and relationship with workplace design in office]. Stockholm: Arbetarskyddsverket, 1988. (Arbete och hälsa; 17.) (English summary.)

Received for publication: 27 September 1991 